\title{
A genetic model of substrate deprivation therapy for a glycosphingolipid storage disorder
}

\author{
Yujing Liu, ${ }^{1}$ Ryuichi Wada, ${ }^{1}$ Hiromichi Kawai, ${ }^{1}$ Kazunori Sango, ${ }^{1}$ Chuxia Deng, ${ }^{1}$ \\ Tadashi Tai, ${ }^{2}$ Michael P. McDonald, ${ }^{3}$ Kristlyn Araujo, ${ }^{3}$ Jacqueline N. Crawley, ${ }^{3}$ \\ Uwe Bierfreund, ${ }^{4}$ Konrad Sandhoff, ${ }^{4}$ Kinuko Suzuki, ${ }^{5}$ and Richard L. Proia ${ }^{1}$ \\ ${ }^{1}$ Genetics of Development and Disease Branch, National Institute of Diabetes and Digestive and Kidney Diseases, \\ National Institutes of Health, Bethesda, Maryland 20892, USA \\ ${ }^{2}$ Department of Tumor Immunology, The Tokyo Metropolitan Institute of Medical Sciences, Tokyo 113-8613, Japan \\ ${ }^{3}$ Section on Behavioral Neuropharmacology, Experimental Therapeutics Branch, National Institute of Mental Health, \\ National Institutes of Health, Bethesda, Maryland 20892, USA \\ ${ }^{4}$ Kekulé-Institut für Organische Chemie und Biochemie der Universität Bonn, 53121 Bonn, Germany \\ ${ }^{5}$ Department of Pathology and Laboratory Medicine, The University of North Carolina, Chapel Hill, Chapel Hill, \\ North Carolina 27599, USA
}

Address correspondence to: Richard L. Proia, Building 10, Room 9D-20, 10 CENTER DR MSC 1810, National Institutes of Health, Bethesda, Maryland 20892, USA. Phone: (301) 496-6774; Fax: (301) 496-9878; E-mail: proia@nih.gov

Yujing Liu's present address is: Department of Pediatrics, Georgetown University Medical Center, Washington, DC 20007, USA

Received for publication October 19, 1998, and accepted in revised form December 22, 1998.

\begin{abstract}
Inherited defects in the degradation of glycosphingolipids (GSLs) cause a group of severe diseases known as GSL storage disorders. There are currently no effective treatments for the majority of these disorders. We have explored a new treatment paradigm, substrate deprivation therapy, by constructing a genetic model in mice. Sandhoff's disease mice, which abnormally accumulate GSLs, were bred with mice that were blocked in their synthesis of GSLs. The mice with simultaneous defects in GSL synthesis and degradation no longer accumulated GSLs, had improved neurologic function, and had a much longer life span. However, these mice eventually developed a late-onset neurologic disease because of accumulation of another class of substrate, oligosaccharides. The results support the validity of the substrate deprivation therapy and also highlight some limitations.
\end{abstract}

J. Clin. Invest. 103:497-505 (1999).

\section{Introduction}

The glycosphingolipid (GSL) storage diseases are caused by genetic disruption in the lysosomal degradation pathway of GSLs $(1,2)$. These disorders include Tay-Sachs disease, Sandhoff's disease, Gaucher's disease, Fabry's disease, Krabbe's disease, and several others. In most of these diseases, GSLs accumulate to massive levels in cells, particularly in neurons, causing neurodegeneration and a shortened life span.

Neurons are primary sites of GSL storage because gangliosides - sialylated GSLs - are normal and relatively abundant constituents of neuronal membranes (1). GSLs are synthesized by the sequential addition of monosaccharides to ceramide by multiple Golgi membrane-bound glycosyltransferases (Fig. 1). The relatively simple gangliosides $G_{M 3}$ and $G_{D 3}$ are produced by the monosialylation and disialylation, respectively, of lactosylceramide. Synthesis of the more complex gangliosides is dependent on the subsequent action of $\beta 1,4-N$-acetylgalatosaminyltransferase (GalNAcT, $\mathrm{G}_{\mathrm{M} 2} / \mathrm{G}_{\mathrm{A} 2}$ synthase; EC 2.4.1.94). After transport to the plasma membrane, the GSLs are ultimately delivered to lysosomes for degradation. Their degradation involves the stepwise removal of individual saccharides through the concerted action of lysosomal enzymes and activator proteins. In the GSL storage diseases, the absence of particular enzymes or activator proteins blocks the degradation pathway and leads to accumulation of GSL substrates unique to each disease .

An emerging strategy for the treatment of these diseases is substrate deprivation therapy $(3,4)$. In this approach, a specific inhibitor of GSL biosynthesis is used to reduce lysosomal storage by lowering the synthetic rate to more closely approximate the compromised rate of degradation. Platt et al. (4) demonstrated the potential validity of this approach with the oral administration of $\mathrm{N}$ butyldeoxynojirimycin (NB-DNJ), an inhibitor of the first glycosyltransferase in GSL synthesis, to a Tay-Sachs disease mouse model that had central nervous system (CNS) storage of GSLs, but which was without clinical manifestations. This regimen substantially lowered brain levels of abnormally stored GSLs in the model mice.

Although the results suggest that the strategy may ultimately lead to an effective treatment for the GSL storage diseases, a number of important issues remain. These include the expected clinical benefit of the therapy, potential deleterious effects of GSL depletion, and the diseases most suitable for the therapy. We have addressed these issues by constructing a genetic model of substrate deprivation therapy for a GSL storage disease through the establishment of mice with simultaneous blocks in GSL synthesis and degradation pathways. 


\section{Methods}

Generation of GalNAcT $T^{-1-}$ and Hexb ${ }^{-/-}$GalNAcT $T^{-1}$ double knockout mice. Genomic clones from a 129/Sv strain library (catalog no. 946306; Stratagene, La Jolla, California, USA) containing the mouse GalNAcT gene were isolated by using a mouse GalNAcT cDNA probe (5). One genomic clone was used to construct the targeting vector containing a $7.8-\mathrm{kb}$ genomic DNA sequence. The targeting vector $(20 \mu \mathrm{g})$ was linearized and electroporated into $2 \times 10^{7} \mathrm{TC} 1$ embryonic stem (ES) cells (6) in a volume of 0.8 $\mathrm{ml}$ at $400 \mathrm{~V}$ and $25 \mu \mathrm{F}$ (Bio-Rad Laboratories Inc., Hercules, California, USA). The G418, ganciclovir-resistant ES cells were obtained and screened by Southern analysis. Chimeric mice were established from targeted ES cells as described (6).

Male $\mathrm{Hexb}^{-/-}$mice were crossed to female GalNAcT $T^{-/}$mice to generate $\mathrm{Hexb}^{+/-}$GalNAcT ${ }^{+/-}$mice. These double heterozygous mice were crossed to generate $H e x b^{-/-}$GalNAcT $T^{-/}$double knockout mice. The knockout mice were a combination of C57BL/6 and 129/Sv strains.

Behavioral analysis. Sixty-four mice $\left(10 \mathrm{Hexb}^{+/+} \mathrm{GalNAcT}^{+/+}: 6\right.$ males, 4 females; $16 \mathrm{Hexb}^{+/+}$GalNAcT ${ }^{-/-}: 8$ males, 8 females; 14 $\mathrm{Hexb}^{-/-} \mathrm{GalNAcT}^{+/+}: 10$ males, 4 females; $10 \mathrm{Hexb}^{-/-}$GalNAcT $^{+/-}: 3$ males, 7 females; and $14 \mathrm{Hexb}^{-/-}$GalNAcT ${ }^{-1}$ : double knockouts, 7 males, 7 females) completed 8 weeks of behavioral testing. Mice that survived longer completed additional behavioral testing. All mice were 11 weeks old at the start of behavioral testing. Mice were group-housed by gender, 2 to 5 per cage. Food and water were freely available in the home cages. The colony room was maintained on an artificial 12-h light/12-h dark cycle, with lights on at $6 \mathrm{am}$.

Rotorod. The ability to maintain balance on a rotating cylinder was measured with a commercially available rotorod apparatus (Model 7650; Ugo Basile, Varese, Italy). The cylinder was $3.2 \mathrm{~cm}$ in diameter with a surface of scored plastic. Mice were confined to a section of the cylinder $6.0 \mathrm{~cm}$ long by black Plexiglas dividers. Each mouse was placed on the cylinder, which increased rotation speed from 5 to $40 \mathrm{rpm}$ over a 5 -min period. The primary measure of interest was the latency at which mice either fell off the rotorod or clung to the rod while it turned one full rotation. Mice that did not fall or cling during the 300-s trial period were removed and given a score of 300 . Rotorod performance was measured once every 2 weeks for 8 weeks.

Righting reflex. Mice were tested at 17 and 23 weeks old. Righting reflex was measured by turning the mouse on its back on a flat stainless steel surface. Latency to turn itself upright was recorded. Mice not righting themselves within $10 \mathrm{~s}$ were turned right-side up and assigned a score of 10.

Statistical analysis. Group comparisons were made using ANOVA. Analyses of performance over time were made using repeated measures ANOVA (RMANOVA), with genotype as a between-subjects factor and age at testing as the repeated measure. Follow-up comparisons of repeated-measures data were made using single-factor and two-group RMANOVA or Bonferroni-corrected $t$ tests.

Biochemical analysis. The analysis of lipids followed a method described previously (7). Fluorophore-assisted carbohydrate electrophoresis (FACE) was used for urinary oligosaccharide analysis with a kit from Glyko Inc. (Novato, California, USA) (8). Urine samples were normalized by using a creatinine quantitative kit (catalog no. 555-A; Sigma Chemical Co., St. Louis, Missouri, USA). Aliquots of urine were incubated overnight at $37^{\circ} \mathrm{C}$ with the ANTS (8-aminonaphthalene 1,3,6-trisulfonic acid, disodium salt) reagent followed by high-resolution PAGE and visualization using the FACE imaging system (Glyko Inc.).

Pathology. Mice with different genotypes and age were studied, including two 4.5-month-old $\mathrm{Hex}^{+/+}$GalNAcT ${ }^{-/}$, two 4.5-monthold Hexb $b^{-/-}$GalNAcT $^{4 /+}$, two 4.5-month-old Hexb $b^{-/-}$GalNAcT $^{4 /-}$, two 4.5-month-old $\mathrm{Hexb}^{-/-}$GalNAcT ${ }^{-/}$, two 8.5-month-old $\mathrm{Hexb}^{+/+}$GalNAcT $T^{-/}$, and two 8.5-month-old Hexb-/- GalNAcT ${ }^{-/}$. Mice were anesthetized and perfused with phosphate-buffered $4 \%$ paraformaldehyde ( $\mathrm{pH} 7.4$ ). The brain, spinal cord, and pieces of visceral organs were processed for paraffin sections, cut and stained with Solochrome/eosin, hematoxylin/eosin (H\&E), Luxol fast blue/periodic acid-Schiff, and Bielschowsky's stains. The tissues for frozen sections were immersed in fixative overnight. After cryoprotection by immersion in $0.1 \mathrm{M}$ phosphate buffer ( $\mathrm{pH} 7.4$ ) containing $20 \%$ sucrose, the tissues were snap frozen and sections were stained with PAS. For electron microscopic analysis, tissues were processed for embedding in plastic resin. Sections (1 $\mu \mathrm{m}$ thick) were cut and stained with toluidine blue. Appropriate areas for further thin sectioning were selected under light microscopy and trimmed for ultrathin sectioning. Sections were double stained with uranyl acetate and lead citrate and examined with a Zeiss 10a electron microscope.

Immunochemistry. The mice examined were 4.5-month-old wild-type, $\mathrm{Hexa}^{-/-}$, Hexb-/- GalNAcT T/+, and Hexb-/- GalNAcT ${ }^{-/-}$ mice. The brains, spinal cords, kidneys, livers, and spleens

\section{Figure 1}

Partial synthesis pathway of GSLs. $\mathrm{G}_{\mathrm{A} 2}$ glycolipid, GalNAc $\beta 1^{\prime}$ $4 \mathrm{Gal} \beta 1^{\prime} 4 \mathrm{Glc} \beta 1^{\prime} 1 \mathrm{Cer}$, and $\mathrm{G}_{\mathrm{M} 2}$ ganglioside, GalNAc $\beta 1^{\prime}$ $4\left(\right.$ NeuAc $\left.\alpha 2^{\prime} 3\right) \mathrm{Gal}^{\prime} \beta 1^{\prime} 4 \mathrm{Glc} \beta 1^{\prime} 1 \mathrm{Cer}$, are highlighted as the major glycolipid storage products in the Sandhoff's disease model mice. $\mathrm{G}_{\mathrm{M} 3}$ : NeuAc $\alpha 2^{\prime} 3 \mathrm{Gal} \beta 1^{\prime} 4 \mathrm{Glc} \beta 1^{\prime} 1 \mathrm{Cer} ; \mathrm{G}_{\mathrm{D} 3}$ : NeuAc $\alpha 2^{\prime}$ 8NeuAc $\alpha 2^{\prime}$ 3Gal $\beta 1^{\prime}$ 4Glc $\beta 1^{\prime} 1 \mathrm{Cer} ; \mathrm{G}_{\mathrm{D} 2}$ : Gal-

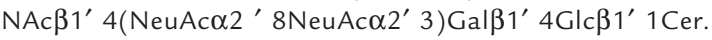
Note that the gene encoding GalNAcT is known as Galgt1 and was formally known as Ggm2 (5). Cer, ceramide; GSLs, glycosphingolipids.

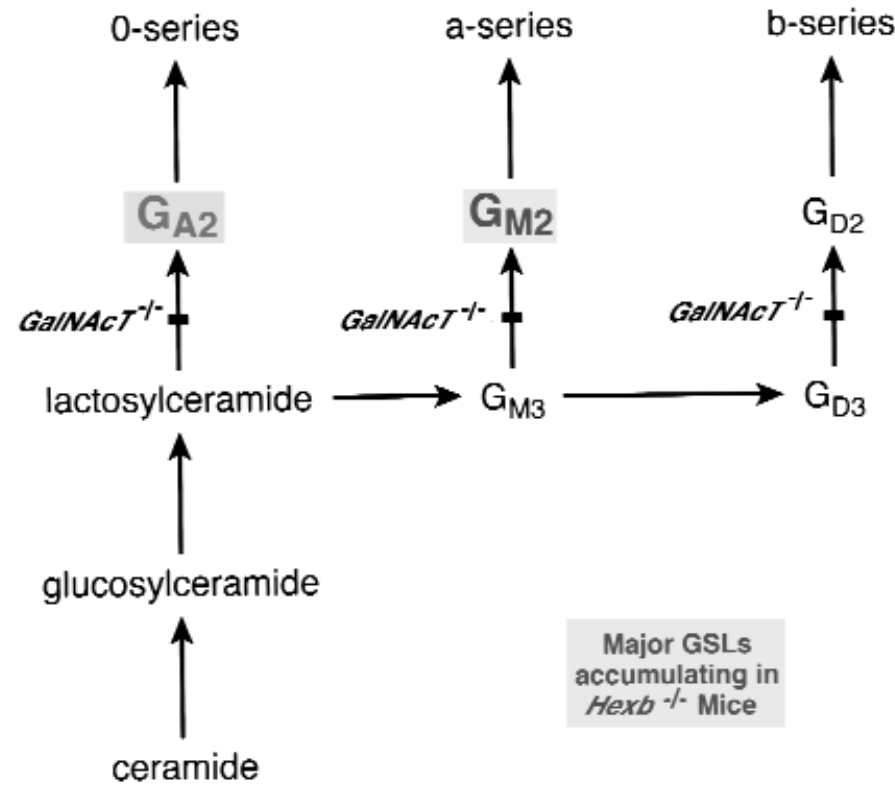


a
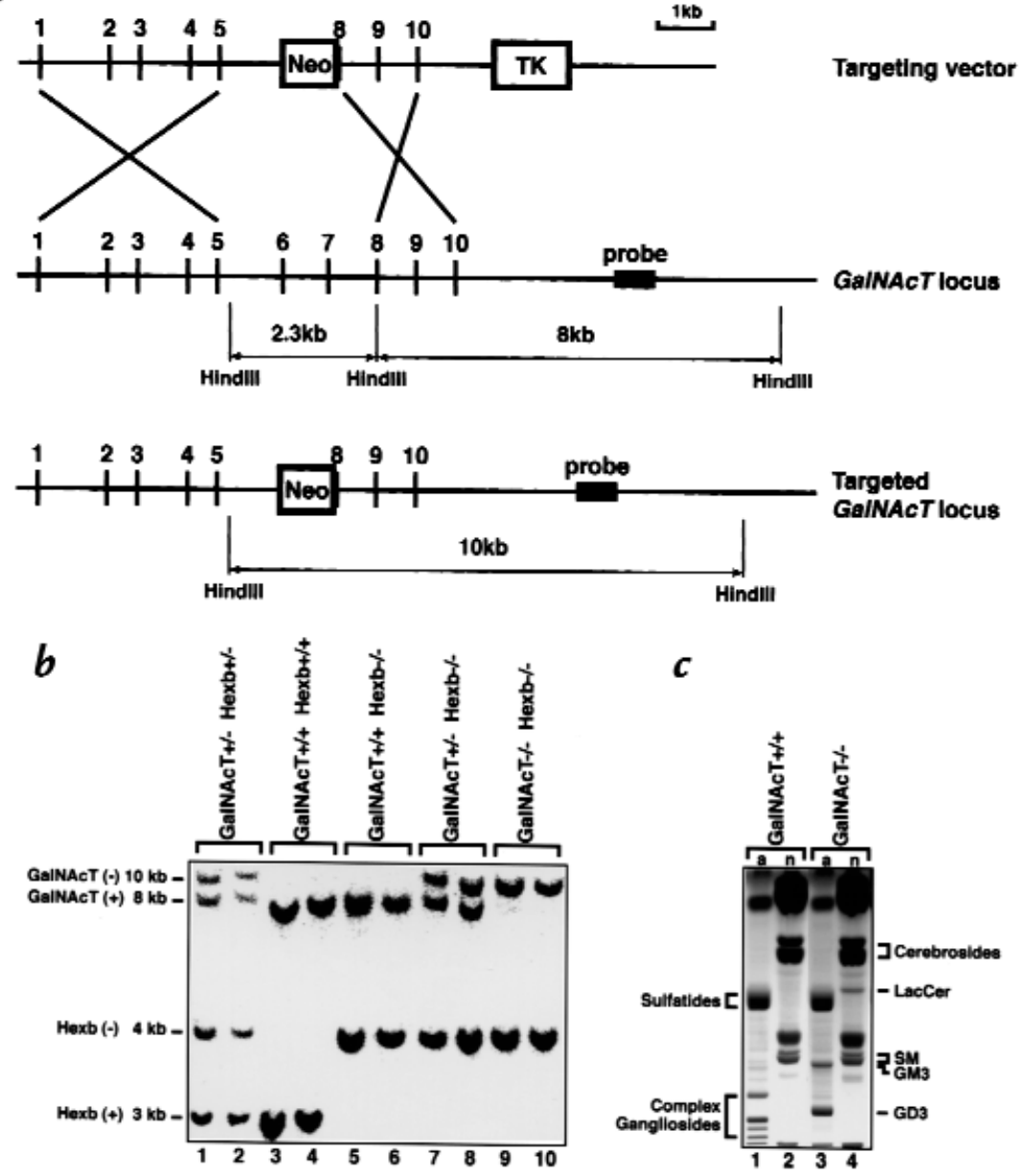

Figure 2

Targeted disruption of the GaINAcT locus and generation of $\mathrm{Hexb}^{-/}$GalNAcT-/- double knockout mice. (a) The structure of the mouse GalNAcT targeting vector is on the top, the structure of the mouse GalNAcT locus is in the middle, and the predicted structure of the homologously recombined locus is on the bottom. ( $\boldsymbol{b}$ ) Genotyping of mouse offspring from the Hexb+l- GalNAcT ${ }^{+/-}$double heterozygous mating. Genomic DNA was isolated from mouse tails, digested with HindIII endonuclease, electrophoresed on a $1 \%$ agarose gel, and transferred to a nylon membrane. The hybridization was performed with both the Hexb probe (11) and GalNAcT probe simultaneously, a. Wild-type Hexb locus yielded a 3-kb HindIII band. Disrupted Hexb locus yielded a 4-kb HindIII band. Wild-type GalNAcT locus showed an 8-kb HindIII band. Targeted GalNAcT locus showed a 10-kb HindIII band. (c) TLC analysis of acidic ( $a$; lanes 1 and 3 ) and neutral ( $n$; lanes 2 and 4 ) lipid fractions from brains of GalNAcT ${ }^{+/+}$mice and GalNAcT ${ }^{-1-}$ mice. were removed, embedded in O.C.T. compound (Sakura Finetek USA Inc., Torrance, California, USA) and quickly frozen in liquid nitrogen.

$\mathrm{G}_{\mathrm{M} 2}$ and $\mathrm{N}$-linked oligosaccharide storage was detected by an indirect immunofluorescence method using anti- $\mathrm{G}_{\mathrm{M} 2}(9)$ anti-Nlinked oligosaccharide (10) monoclonal antibody. The latter antibody binds $\mathrm{N}$-linked oligosaccharides with a nonreducing terminal $\beta$-linked GlcNAc residue. Frozen sections ( $7 \mu \mathrm{m}$ thick) were fixed in cold acetone for $10 \mathrm{~min}$ and air dried. After rehydration in PBS, the sections were incubated with $5 \%$ normal goat serum in PBS for $1 \mathrm{~h}$. The culture supernatant from mouse hybridomas GMB28 (9) (anti-G $\mathrm{M}_{\mathrm{M}}$ ) and OMB4 (10) (anti-Nlinked oligosaccharide) were then applied to the sections, and the slides were incubated at room temperature for $1 \mathrm{~h}$. After rinsing with PBS, the sections were incubated with FITC-labeled anti-mouse IgM antibody (Sigma Chemical Co.) for $1 \mathrm{~h}$. The fluorescence was observed under a Leica fluorescence microscope.

\section{Results}

Experimental design. We have previously produced a clinically and pathologically accurate mouse model of Sandhoff's disease through the disruption of the gene (Hexb) encoding the $\beta$ subunit of $\beta$-hexosaminidase (11). These mice are deficient in both $\beta$-hexosaminidase $A(\alpha \beta)$ and $\mathrm{B}(\beta \beta)$, the major forms of lysosomal $\beta$-hexosaminidase. Their nearly total $\beta$-hexosaminidase deficiency - only a very small amount of $\beta$-hexosaminidase $S(\alpha \alpha)$ remains
- renders the mice compromised in their ability to degrade $\mathrm{G}_{\mathrm{M} 2}$ ganglioside and the related $\mathrm{G}_{\mathrm{A} 2}$ glycolipid. As in the human disease, these glycolipids accumulate in neurons causing apoptosis (12), progressive loss of motor behaviors, and a severely shortened life span (11).

To investigate consequences of totally eliminating $\mathrm{G}_{\mathrm{M} 2}$ ganglioside and $\mathrm{G}_{\mathrm{A} 2}$ glycolipid synthesis in Sandhoff's disease mice, we first generated mice deficient in GalNAcT. GalNAcT transfers $N$-acetylgalactosamine onto glycolipid acceptors to produce complex glycolipids, including $\mathrm{G}_{\mathrm{A} 2}$ and $\mathrm{G}_{\mathrm{M} 2}$ (Fig. 1). The GalNAcT gene was disrupted by a replacement-type targeting vector in which exon 6 , exon 7 , and part of exon 8 were deleted and replaced with the MC1NeoPolyA (13) selection cassette (Fig. 2a). GalNAcT ${ }^{-/-}$ mice were obtained through heterozygous matings with a frequency expected from mendelian inheritance, suggesting the absence of embryonic lethality. The inactivation of the GalNAcT gene was proven by Northern analysis: no GalNAcT-related transcripts were detected in the brain and liver of GalNAcT T/- mice (not shown).

Because of the absence of GalNAcT, these mice were unable to synthesize complex gangliosides normally present in the brain (Fig. $2 c$, lane 1). The complex gangliosides (Fig. 2c, lane 1) were replaced by $\mathrm{G}_{\mathrm{M} 3}, \mathrm{G}_{\mathrm{D} 3}$, and lactosylceramide in the brains of the GalNAcT ${ }^{-/-}$mice (Fig. 2c, lanes 3 and 4), structures synthesized before the 
block at GalNAcT (Fig. 1).

Despite the striking absence of complex ganglioside structures, the GalNAcT $T^{-/}$mice were grossly normal at 12 months old. This finding is similar to the previously generated GalNAcT knockout mice, in which the neo gene was simply inserted into exon 4 of the gene (14), even though our mice were created with a more severe, multiexon gene deletion.

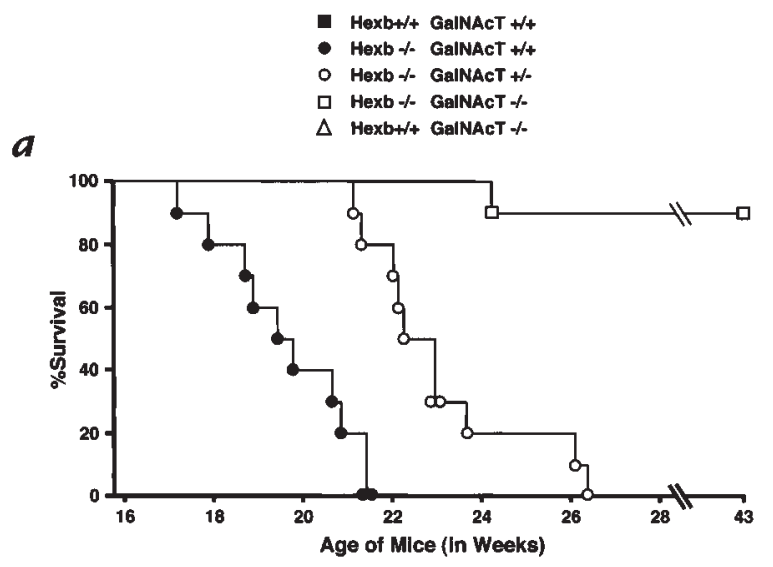

$\boldsymbol{b}$

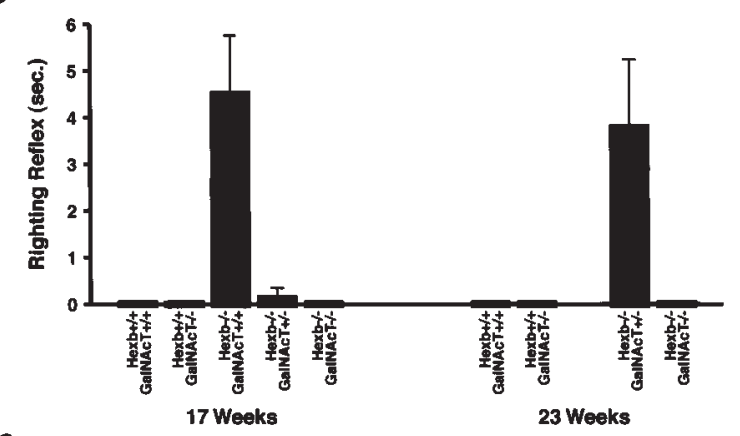

$c$

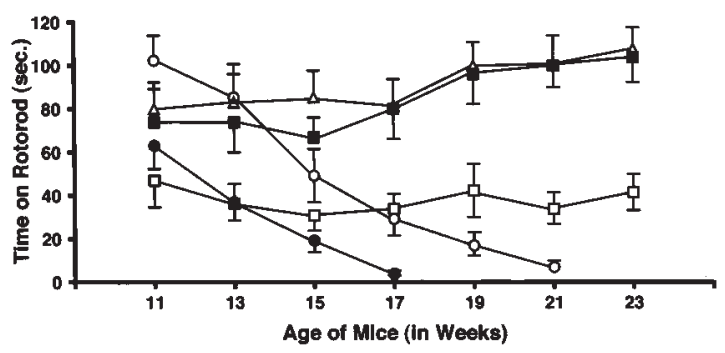

Figure 3

Life span and behavioral testing. (a) Survival of the Hexb-/- mice with different GalNAcT backgrounds. Each group contained 10 mice. (b) Mean ( \pm SEM) righting reflex for $\mathrm{Hexb}^{+/+} \mathrm{GaINAcT}^{+/+}(n=10), \mathrm{Hexb}^{+/+} \mathrm{GalNAcT}^{-/-}(n=$ 16 at 17 weeks; $n=15$ at 23 weeks), Hexb ${ }^{-/-}$GalNAcT $^{+/+}(n=14)$, Hexb $^{-/-}$Gal$\mathrm{NAcT}^{+/-}(n=10$ at 17 weeks; $n=5$ at 23 weeks $)$, and Hexb ${ }^{-/-}$GalNAcT $T^{-1-}$ double knockouts $(n=14)$. All Hexb $b^{-/-}$GalNAcT $T^{+/}$mice were dead by 23 weeks old. Hexb-/- GalNAcT ${ }^{\text {/+ }}$ mice had a significantly impaired righting reflex compared with all other groups at 17 weeks old. Hexb-/- GalNAcT $T^{+/-}$mice had a significantly impaired righting reflex compared with all other groups at 23 weeks old. (c) Mean ( \pm SEM) time to fall off the rotorod. Group size at all time points: $\mathrm{Hexb}^{+/+} \mathrm{GalNAcT}^{+/+}(n=10), \mathrm{Hexb}^{+/+} \mathrm{GaINAcT}^{-/-}(n=16), \mathrm{Hexb}^{-/-}$ GalNAcT ${ }^{+/+}(n=14), \mathrm{Hexb}^{-/-}$GalNAcT ${ }^{+-}(n=9)$, and Hexb-/- GalNAcT-/- double knockouts $(n=14)$ were tested. The lowered variability of the $\mathrm{Hexb}^{-/-} \mathrm{Gal}-$ $\mathrm{NAcT}^{+/+}$and $\mathrm{Hexb}^{-/-}$GalNAcT $\mathrm{T}^{+/-}$mice at later times probably reflects their worsening condition and their limited ability to perform the task.
A major phenotypic finding related to the absence of complex gangliosides in the GalNAcT $\mathrm{T}^{-/}$mice was male infertility caused by degeneration of seminiferous tubules (not shown). Female GalNAcT $T^{-1-}$ mice were fertile.

Life span and behavioral analysis. We generated $\mathrm{Hexb}^{-/-} \mathrm{Gal}$ $N A c T^{-1}$ - double knockout mice through matings of double heterozygotes (Fig. 2b). In the same crosses, Hexb-/- GalN$\mathrm{AcT}^{+/+}$and $\mathrm{Hexb}^{-/-}$GalNAcT ${ }^{+/-}$mice were also obtained. The life span of each group of mice $(n=10)$ was evaluated (Fig. $3 a)$. The mice in the Hexb-/- GalNAcT ${ }^{+/+}$group died 120-150 days after birth, following the onset of a rapid neurodegenerative disease course (11). The group of $\mathrm{Hexb}^{-/-}$GalNAcT $\mathrm{T}^{+-}$mice showed a very similar but slightly delayed disease course; they lived until 149-184 days after birth, a significantly longer period than the Hexb-/- GalN$A c T^{4 /+}$ mice $(P=0.0002)$. During the $300-$ day duration of the experiment, 9 of 10 double knockout mice remained viable; a double knockout mouse died at 170 days after birth for unknown reasons. All of the $\mathrm{Hexb}^{+/+} \mathrm{GalNAcT}^{-/}$ mice survived the testing period.

Mice of different genotypes were tested on two behavioral tasks, righting reflex and rotorod, that have been proven to monitor the progressive disease course of the Hexb $b^{-/-}$mice $(11,15)$. The Hexb-/- mice likely become progressively impaired in these tasks as a result of CNS storage, motor neuron damage, and muscle wasting evident in the disease (16). In the righting reflex task, the mice are placed on their backs, and the time to right themselves is recorded. Normal mice right themselves immediately. As they age, the Hexb-/- mice show a decline in righting reflex. In the rotorod task, a measure of motor function and coordination, the time that the mice can remain on a rotating cylinder is determined. The $\mathrm{Hexb}^{-/-}$mice show a progressive decline in their ability to remain on the rotorod (11).

There were significant differences across groups on the righting reflex, measured at 17 weeks old $\left(F_{4,59}=12.12, P\right.$ $<0.0001$ ) (Fig. 3b). Post hoc analyses showed that the $\mathrm{Hexb}^{-/-}$GalNAcT $\mathrm{T}^{+/+}$mice had a significantly impaired righting reflex, compared with all other groups (all $t$ 's $>$ 2.99; all $P$ 's < 0.0068). None of the other group comparisons were significant at 17 weeks old, showing that the double knockout and $\mathrm{Hexb}^{-/-}$GalNAcT ${ }^{+/-}$mice were not impaired at this time. However, at 23 weeks old, the Hexb-/- GalNAcT ${ }^{4 /-}$ mice had a significantly impaired righting reflex, compared with all other groups (all $t$ 's $>$ 4.12; all $P$ 's < 0.0013). None of the other group comparisons was significant at this age demonstrating that the double knockout mice were not impaired in this task. By 23 weeks old, the $\mathrm{Hexb}^{-/-}$GalNAcT $T^{4 /+}$ mice had died.

As shown in Fig. $3 c$, rotorod performance - a measure of balance and mobility - during the period that the $\mathrm{Hexb}^{-/-}$GalNAcT $\mathrm{T}^{+/+}$mice remained viable (11-17 weeks) differed greatly across the five groups $\left(F_{4,59}=9.03 ; P<\right.$ $0.0001)$ and over the six-week testing period $\left(F_{3,177}=\right.$ $10.17 ; P<0.0001)$. In addition, there was a significant Genotype X Age interaction $\left(F_{12,177}=3.32 ; P=0.0002\right)$, indicating that performance of some mice deteriorated significantly over the six-week testing period, while performance of other mice did not change significantly. Planned follow-up comparisons showed that rotorod performance of the $\mathrm{Hexb}^{-/-}$GalNAcT T/+ mice was signifi- 


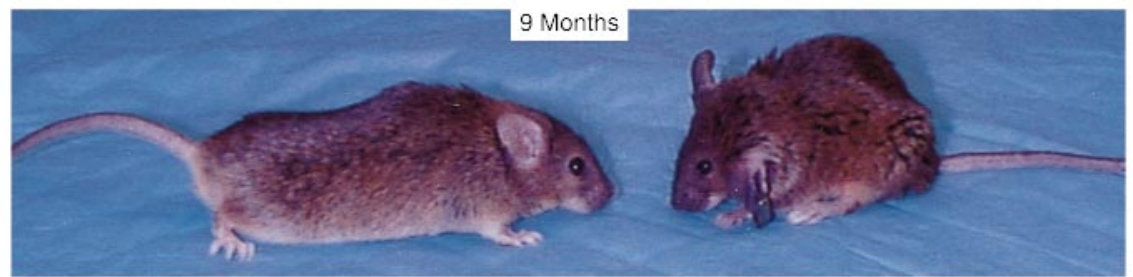

Hexb ${ }^{+1+}$

GalNACT $\%$
Hexb-1-

GalNACT ${ }^{-1-}$
Figure 4

Nine-month-old Hexb-/- GalNAcT-/- double knockout mice shown with an age-matched GalNAcT $T^{-/}$single knockout mouse. Note the hunched posture and disheveled condition of the double knockout mouse. cantly worse than that of the control mice $\left(F_{1,22}=15.57\right.$; $P<0.0001)$, replicating results from previous studies (7, $11,15)$. Rotorod performance of the double knockout mice was significantly worse than that of the control mice $\left(F_{1,22}=9.22 ; P=0.0061\right)$. However, the performance of the double knockout mice remained stable with increasing age, compared with the rapidly deteriorating performance of the $\mathrm{Hexb}^{-/-}$GalNAcT ${ }^{4 /+}$ mice $\left(F_{3,78}=4.86\right.$; $P=0.0038)$. The $\mathrm{Hexb}^{-/-}$GalNAcT ${ }^{4-}$ group performed significantly better overall than both the Hexb ${ }^{-/-} \mathrm{GalNAcT}^{+/+}$ group $\left(F_{1,22}=16.99 ; P=0.0004\right)$ and the double knockout group $\left(F_{1,22}=8.49 ; P=0.008\right)$. However, the performance of the $\mathrm{Hexb}^{-/-}$GalNAcT ${ }^{+/-}$mice deteriorated much faster than that of the double knockout mice from 11 to 17 weeks old $\left(F_{3,66}=5.87 ; P=0.0013\right)$. The rate of deterioration in the $\mathrm{Hexb}^{-/-}$GalNAcT $\mathrm{T}^{+/}$mice was not different from that of the Hexb $b^{-/-}$GalNAcT $T^{+/+}$mice $\left(F_{3,66}=\right.$ $0.96 ; P=0.419)$. There was no significant difference in rotorod performance between the normal controls and the $\mathrm{Hexb}^{+/+}$GalNAcT ${ }^{-/}$groups $\left(F_{1,24}=0.34 ; \mathrm{P}=0.566\right)$ during this time period.

At 21 weeks old, the last testing time that included the $\mathrm{Hexb}^{-/-}$GalNAcT ${ }^{4--}$ mice, there were significant group differences in rotorod performance $\left(F_{3,44}=18.57 ; P<\right.$ 0.0001). Follow-up comparisons show that the double knockout mice were now performing significantly better than the Hexb $b^{-/-}$GalNAcT $T^{+-}$mice $\left(t_{21}=2.80 ; P=0.0108\right)$.
Rotorod performance of the control mice was significantly better than both the double knockout mice $\left(t_{22}=\right.$ 5.32; $P<0.0001)$ and the Hexb $b^{-/-}$GalNAcT $T^{4-}$ mice $\left(t_{17}=\right.$ 8.16; $P<0.0001)$ at this age. There was no difference in rotorod performance between the control and $\mathrm{Hexb}^{+/+}$ GalNAc $^{-/-}$groups at 21 weeks old $\left(t_{23}=0.03 ; P=0.979\right)$.

Beginning at about seven months old, the double knockout mice began to display an ataxic gait that progressively worsened over time. At nine months old, these mice exhibited severe phenotypic abnormalities, including muscle wasting and hunched posture, while the $\mathrm{Hexb}^{+/+}$GalNAcT $\mathrm{T}^{-1}$ mice appeared normal (Fig. 4).

Glycolipid and oligosaccharide accumulation. Brain gangliosides were isolated from 4.5-month-old mice and analyzed by thin-layer chromatography (TLC) (Fig. 5a). Gangliosides of wild-type mice $\left(\mathrm{Hexb}^{+/+} \mathrm{GalNAcT}^{+/+}\right)$consisted primarily of $\mathrm{G}_{\mathrm{M} 1}, \mathrm{G}_{\mathrm{D} 1 \mathrm{a}}, \mathrm{G}_{\mathrm{D} 1 \mathrm{~b}}$, and $\mathrm{G}_{\mathrm{T} 1 \mathrm{~b}}$ (Fig. $5 a$, lane 1). In $\mathrm{Hexb}^{-/-}$GalNAcT T/++ mice, extensive $\mathrm{G}_{\mathrm{M} 2}$ ganglioside accumulation was superimposed upon the normal pattern of complex gangliosides (Fig. 5a, lane 2). $\mathrm{Hexb}^{+/+} \mathrm{Gal}-$ $N A c T^{-/-}$mice, unable to synthesize most complex gangliosides, exhibited primarily $\mathrm{G}_{\mathrm{M} 3}$ and $\mathrm{G}_{\mathrm{D} 3}$ in the acidic lipid fraction (Fig. $5 a$, lane 3). The acidic lipid pattern of the double knockout mice was virtually indistinguishable from the $\mathrm{Hexb}^{+/+}$GalNAcT ${ }^{-/-}$mice, with primarily $\mathrm{G}_{\mathrm{M} 3}$ and $\mathrm{G}_{\mathrm{D} 3}$ gangliosides and no other abnormally accumulating lipid species (Fig. $5 a$, lane 4). $\mathrm{G}_{\mathrm{M} 2}$ storage was
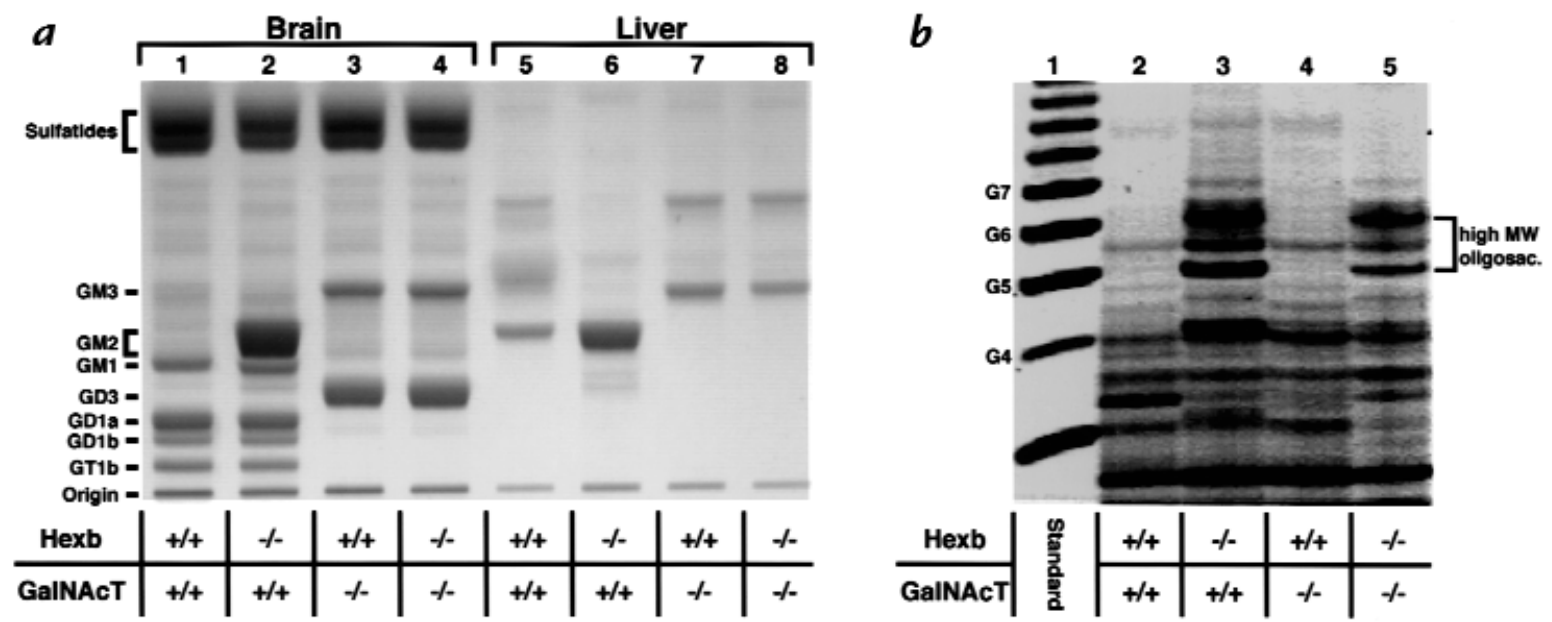

Figure 5

Ganglioside accumulation and urinary oligosaccharide excretion. (a) The acidic fraction of sphingolipids from brain and liver tissues was separated by TLC. The ganglioside standards are indicated. (b) Urine was collected from 4-month-old mice of different genotypes. FACE was performed to analyze urinary oligosaccharides. The size standards consist of glucose polymers. The bracket indicates the high-molecular-weight oligosaccharides present in the Hexb-/- single knockout and Hexb-/- GalNAcT-/- double knockout urine but not the wild-type and GalNAcT-/- urine. FACE, fluorophore-assisted carbohydrate electrophoresis. 

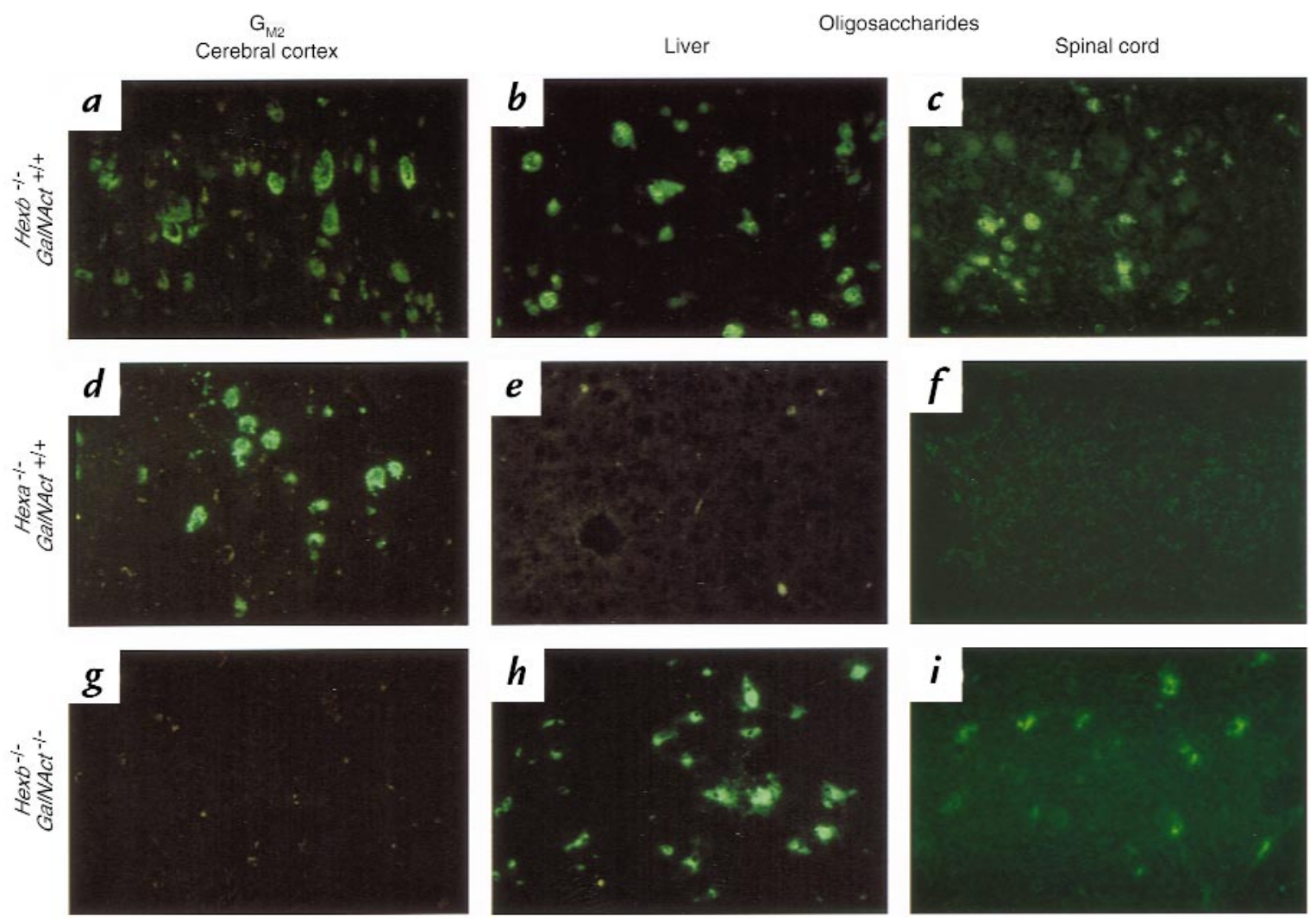

\section{Figure 6}

$\mathrm{G}_{\mathrm{M} 2}$ ganglioside and oligosaccharide accumulation in tissues. Immunofluorescence staining of cerebral cortex, liver, and spinal cord with an anti- $\mathrm{G}_{\mathrm{M} 2}$ ganglioside monoclonal antibody $(\boldsymbol{a}, \boldsymbol{d}, \boldsymbol{g})$ and an anti-oligosaccharide monoclonal antibody $(\boldsymbol{b}, \boldsymbol{c}, \boldsymbol{e}, \boldsymbol{f}, \boldsymbol{h}, \boldsymbol{i}) . \times 100$.

also completely eliminated in the liver in the double knockout mice (Fig. $5 a$, compare lanes 6 and 8 ). Likewise, storage of related $\mathrm{G}_{\mathrm{A} 2}$ glycolipid was absent in the liver and brain of the double knockout mice (not shown).

Because of a block in the degradation of N-linked oligosaccharides caused by the absence of both $\beta$-hexosaminidase A and B, Sandhoff's disease patients and model mice excrete high-molecular-weight oligosaccharides in their urine $(15,17)$ (Fig. 5b, lane 3). The double knockout mice also excreted elevated levels of high-molecular-weight oligosaccharides (Fig. 5b, lane 5), although the amount was about half that in urine of the Hexb ${ }^{-/-}$GalNAcT ${ }^{+/+}$mice. The urinary oligosaccharides were sensitive to digestion with $\beta$ hexosaminidase (not shown). Abnormal high-molecularweight oligosaccharides were not detected in the urine of the Hexb $b^{++}$GalNAcT $T^{--}$mice (Fig. 5b, lane 4).

Tissue storage of $\mathrm{G}_{\mathrm{M} 2}$ ganglioside and $\mathrm{N}$-linked oligosaccharides were assessed using anti- $\mathrm{G}_{\mathrm{M} 2}$ ganglioside (9) and anti-N-linked oligosaccharide monoclonal antibody (10) (Fig. 6). The Tay-Sachs mouse model (18) was examined as a comparison, because although they accumulate $G_{\mathrm{M} 2}$ ganglioside in tissues like the Sandhoff's disease mice, they should not accumulate oligosaccharides because of the retention of $\beta$-hexosaminidase $\mathrm{B}$, which is able to degrade $\mathrm{N}$-linked oligosaccharides but not $\mathrm{G}_{\mathrm{M} 2}$ ganglioside.

In both Hexb-/- (Sandhoff's disease) and Hexal- (TaySachs disease) mice, the distribution of $\mathrm{G}_{\mathrm{M} 2}$ storage detected with antibody was consistent with previous descriptions $(11,19,20) . \mathrm{G}_{\mathrm{M} 2}$ immunostaining was extensive and widely distributed in the CNS of $\mathrm{Hexb}^{-/}$ mice (Fig. 6a, and data not shown). Positively stained neurons were also found in the Hexa-/- mice, although the $\mathrm{G}_{\mathrm{M} 2}$ distribution was restricted to particular regions in the CNS (Fig. $6 d$, and data not shown). $\mathrm{G}_{\mathrm{M} 2}$ storage was not apparent in the double knockout mice (Fig. 6g) or wild-type mice (data not shown).

In Hexa $a^{-/}$mice (Fig. 6, $e$ and $f$ ) and wild-type mice (not shown), anti-oligosaccharide immunostaining revealed no significant storage of oligosaccharides in CNS or visceral organs. In Hexb-/- mice, oligosaccharide storage was detected in cerebellar Purkinje cells (described below), neuronal cells of the cerebral cortex, thalamic nuclei, brainstem, spinal cord (Fig. 6c), and, weakly, in the hippocampus. Double staining with anti-macrophage and anti-oligosaccharide antibodies revealed that significant storage of oligosaccharides was in microglial cells throughout the CNS (not shown).

In the double knockout mice, the neuronal staining with anti-oligosaccharide was detectable but reduced when compared with the Hexb/- GalNAcT ${ }^{+/+}$mice. Microglial cells storing oligosaccharides were easily detected and found scattered throughout regions of the brain and spinal cord (Fig. 6i).

In the visceral organs, oligosaccharide storage was detectable in macrophages in the liver (Fig. 6, $b$ and $b$ ) and spleen as well as in renal tubular epithelium in both the $\mathrm{Hexb}^{-/-} \mathrm{GalNAcT}^{+/+}$and double knockout mice. 
Pathologic analysis. Pathologic differences in 4.5-monthold mice of different genotypes were evaluated. At this age, the $\mathrm{Hexb}^{-/-}$GalNAcT $\mathrm{T}^{+/+}$mice showed severe axonal degeneration in the anterior column of the spinal cord (Fig. 7a, arrows). By contrast, a similar section from the double knockout mice appeared relatively normal (Fig. 7b). Using combined Luxol fast blue (LFB) and periodic acid-Schiff (PAS) staining, storage neurons containing large amounts of blue-staining inclusions were readily observed throughout the cerebral cortex of the Hexb-/- GalNAcT $\mathrm{T}^{+/+}$mice (Fig. $7 c$, arrows). Again, the double knockout mice did not show this severe and conspicuous pathology (Fig. 7d). Perivascular macrophages stained reddish-pink - indicative of storage - were present in the brains of both double knockout and Hexb-/- GalNAcT ${ }^{+/+}$mice (Fig. 7, $c$ and d; arrowheads). Although massive neuronal inclusions were not present in the double knockout (Hexb-/- GalNAcT-/-) mice, some neurons were found to contain fine to coarse vacuoles in their perikarya. These neuronal vacuoles were examined by electron microscopy and compared with the neuronal inclusions found in $\mathrm{Hexb}^{-/-} \mathrm{GalNAcT}^{+/+}$mice. As described previously, the inclusions of the Hexb-/- GalN$\mathrm{AcT}^{+/+}$mice were electron-dense, membranous lamellar structures consistent with GSL storage $(11,20)$ (Fig. 7e). Vacuoles in the double knockout mice were very different in appearance. They were relatively empty with some electron-dense debris (Fig. 7f). This appearance is consistent with storage of water-soluble compounds such as oligosaccharides. These pathologic changes described in the double knockout mice were not observed in the $\mathrm{Hexb}^{+/+}$GalNAcT T/- mice (not shown).

A striking pathologic finding in the double knockout mice was an extensive loss of cerebellar Purkinje cells by 8.5 months old (Fig. $8 a$ ), a time when these mice were exhibiting severe ataxia. No evidence of Purkinje cell degeneration was found in 8.5-month-old $\mathrm{Hexb}^{+/+}$GalNAcT $\mathrm{T}^{-/-}$mice (Fig. 8b).

Using the anti-oligosaccharide antibody, cerebellar Purkinje cells from double knockout (Fig. 8c) and
$\mathrm{Hexb}^{-/-}$GalNAcT ${ }^{+/+}$mice (Fig. $8 d$ ) were found to display a strong granular staining pattern indicative of abnormal substrate accumulation. Little immunoreactivity was seen in the molecular and granular layers. Purkinje cells from $\mathrm{Hexa}^{-/-}$mice and wild-type mice did not show reactivity with the antibody (not shown).

Visceral pathology in the Hexb-/- GalNAcT ${ }^{+/+}$mice, which has been documented previously (11), included vacuolated cells (storage macrophages) in the liver, spleen, and kidney. Renal tubular epithelial cells were also found to be vacuolated. Similar findings were also present in the double knockout mice but not in the $\mathrm{Hexb}^{+/+}$GalNAcT $\mathrm{T}^{-/}$mice. The visceral pathology in the double knockout and the Hexb-/- GalNAcT ${ }^{4 /+}$ mice corresponded well to the distribution of oligosaccharide storage determined by immunostaining. In both the $\mathrm{Hexb}^{+/+}$ GalNAcT $T^{-1-}$ and double knockout mice, degeneration of seminiferous tubules in the testis was pronounced.

\section{Discussion}

Treatments that can reverse or alter progression of the clinical manifestations for GSL storage diseases are limited and not effective for the majority of the disorders. Enzyme replacement is an effective therapy for Type 1 Gaucher's disease, a GSL storage disorder that is unique by the absence of CNS manifestations $(21,22)$. For other disorders that exhibit CNS involvement, enzyme replacement has been difficult to implement thus far because of the inability of enzyme to cross the blood-brain barrier. Recently, bone marrow transplantation has been reported to reverse CNS manifestations in the juvenile form of Krabbe's disease (23) but has been of little value in other disorders (24).

Substrate deprivation therapy has some features that make it an attractive treatment approach for the GSL storage diseases. First, a single inhibitor may be used to treat several of the disorders. NB-DNJ, the most intensively studied drug, blocks the first glycosylation step in the synthesis of glucose-based GSLs (25) and, thus,
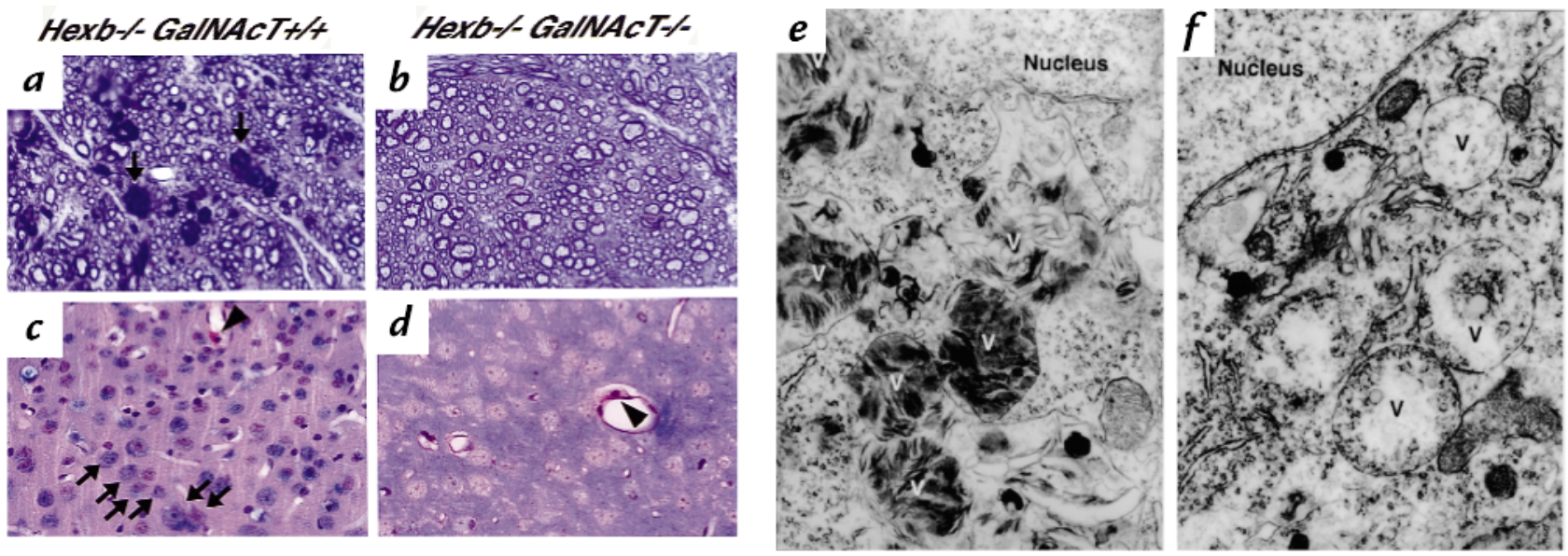

Figure 7

Comparison of pathology between double knockout (Hexb-/- GalNAcT ${ }^{-/-}$) and single knockout (Hexb $b^{-/-}$GalNAcT $\left.T^{+/+}\right)$mice. ( $\boldsymbol{a}$ and $\left.\boldsymbol{b}\right)$ Plastic-embedded spinal cord sections from (a) Hexb-/- GalNAcT $T^{+/+}$and (b) Hexb $b^{-/-}$GalNAcT $T^{-/-}$mice were stained with toluidine blue. Arrows indicate axonal degeneration. $\times 270$. ( $c$ and $\boldsymbol{d}$ ) Paraffin sections of cerebral cortex from $(c) \mathrm{Hexb}^{-/-}$GalNAcT $T^{+/+}$and $(d)$ Hexb-/- GalNAcT-/- mice. Sections were stained with LFB and PAS. Neuronal inclusions were stained blue (arrows) and perivascular macrophages were stained reddish-pink (arrowheads). $\times 110$. $(\boldsymbol{e}$ and $\boldsymbol{f})$ Electron micrographs of anterior horn neurons of spinal cord from $(e)$ Hexb-/- GalNAcT ${ }^{+/+}$and $(f)$ Hexb-/- GalNAcT ${ }^{-/-}$mice. $\times 11,000$. Note differences in the contents of storage vacuoles $(v)$. LFB, Luxol fast blue stain; PAS, periodic acid-Schiff stain. 


\section{Figure 8}

Purkinje cell degeneration in the Hexb ${ }^{-/-}$GalNAcT $T^{-/}$double knockout mice. ( $\boldsymbol{a}$ and $\boldsymbol{b}$ ) H\&E staining of the cerebellum from (a) 8.5-month-old double knockout and (b) 8.5-month-old GalNAcT-1- single knockout mice. Arrows point out Purkinje cells. $\times 110$. ( $\boldsymbol{c}$ and $\boldsymbol{d})$ Immunofluorescence staining of cerebellum with an anti-N-linked oligosaccharide antibody from $(c)$ 4.5-month-old double knockout and (d) 4.5-monthold $\mathrm{Hexb}^{-1-}$ single knockout mice. $\times 130$. Arrows point out Purkinje cells. $H \& E$, hematoxylin and eosin.
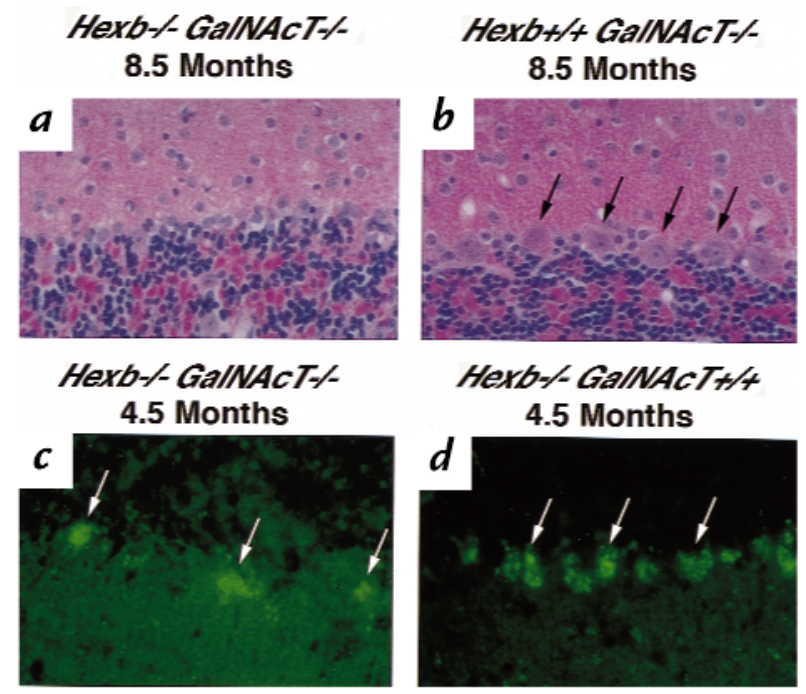

could be used to treat all storage diseases with defects in the degradation of glucose-based GSLs. Second, NB-DNJ crosses the blood-brain barrier to alter GSL storage levels (4) and would potentially influence the CNS manifestations dominant in the majority of the diseases. And finally, substrate deprivation therapy is noninvasive in contrast to the other available treatments: bone marrow transplantation and enzyme replacement.

We have developed a genetic model of substrate deprivation therapy for a GSL storage disease - Sandhoff's disease - that has allowed investigation into questions of potential efficacy and limitations. To achieve specific and complete elimination of GSL storage, a GalNAcT (Galgt1) knockout mouse was generated that was unable to synthesize the majority of complex gangliosides. Introduction of the disrupted GalNAcT gene into the Sandhoff's disease background yielded mice with simultaneous blocks in GSL synthesis and degradation.

Extent of symptom elimination. The double knockout mice were totally devoid of the major GSL storage substrates normally found in Sandhoff's disease mice. This resulted in the absence of the massive neuronal storage and the very severe pathology that is a defining feature of the disease (11). The life span of the mice was extended from about 4-5 months to over 12 months, and the rapid neurodegeneration characteristic of the disease was not present.

The small reduction of GSL storage in the $\mathrm{Hexb}^{-/-} \mathrm{Gal}$ $\mathrm{NAcT}^{+/-}$mice increased their life span by only $18 \%$ and illustrated the importance of balancing the rates of substrate synthesis and degradation for the prevention of a lysosomal storage disease (26). The Sandhoff's disease model is similar to infantile disease forms, which have very little GSL degradative activity. Only a nearly complete reduction in GSL synthesis, as in the double knockout mice, would be expected to rescue the disease phenotype. The partial reduction of GSL synthesis afforded by NB-DNJ would be anticipated to be more beneficial in later onset forms of the diseases, which have significant residual degradative activities, in contrast to the infantile forms. Increased effectiveness of substrate deprivation therapy in infantile diseases may be achieved by raising degradative capacity through enzyme replacement, gene therapy, or cell transplantation therapy.
The complete elimination of abnormal GSL storage in the double knockout mice did not completely restore neurologic function to control levels. Eventually the double knockout mice began to exhibit ataxia that progressively worsened over time. The accumulation of a second $\beta$-hexosaminidase substrate, $\mathrm{N}$-linked oligosaccharide, appears a likely contributor to the disease phenotype of double knockout mice. Although N-linked oligosaccharide storage in Sandhoff's disease patients has been well documented (17), its contribution to nervous system pathology and dysfunction has been difficult to discern because of the dominant GSL storage. Our studies with anti-oligosaccharide antibody indicate this storage is widespread in the CNS and may contribute to a striking loss of cerebellar Purkinje cells in the double knockout mice. Oligosaccharide storage was also found to be widely distributed in other tissues of the double knockout mice and may be responsible for much of the visceral pathology in Sandhoff's disease. Storage of oligosaccharides in tissues and their excretion in urine appeared to be more pronounced in the single knockout Sandhoff's disease mice than in the double knockout mice. The difference may be due to a nonspecific impairment of lysosomal function by the additional storage of GSLs in the Sandhoff's disease mice, as has been described in Gaucher's disease (27).

Proteoglycans are also substrates for $\beta$-hexosaminidase. However, previous studies on mice with a total hexosaminidase deficiency $\left(\mathrm{Hexa}^{-/-} \mathrm{Hexb}^{-/-}\right)$indicated that $\beta$ hexosaminidase $S$, present in Sandhoff's disease mice, is sufficient to prevent significant pathology associated with proteoglycan storage $(7,28)$. While the Sandhoff's and double knockout mice (Hexb-/- GalNAcT ${ }^{-/}$) are without the characteristic pathology of mucopolysaccharidosis, indicating that proteoglycans are likely not a major pathogenic factor, a minor contribution to pathogenesis by this substrate is difficult to totally rule out.

Potential for secondary storage disease after substrate deprivation therapy. In most of the GSL storage diseases, GSLs are the exclusive substrate stored in tissues. With Tay-Sachs disease, the presence of $\beta$-hexosaminidase $B$ is sufficient to preclude the storage of $\mathrm{N}$-linked oligosaccharides that occurs in Sandhoff's disease. Other disorders with exclu- 
sive storage of GSL substrates include Gaucher's disease, Fabry's disease, and the activator deficiencies. In all these cases, secondary storage diseases after GSL depletion would not appear to be a concern.

$\mathrm{G}_{\mathrm{M} 1}$ gangliosidosis ( $\beta$-galactosidase deficiency) (29), like Sandhoff's disease, would have the potential for developing a secondary storage disease after depletion of GSLs. In $\mathrm{G}_{\mathrm{M} 1}$ gangliosidosis, oligosaccharides and proteoglycans are stored along with GSLs and appear to contribute significantly to the disease manifestations. In the later onset forms of Sandhoff's disease and $\mathrm{G}_{\mathrm{M} 1}$ gangliosidosis, which have residual levels of degrading activity, the role of non-GSL substrates in pathogenesis is not known. The possibility exists that the residual enzyme activity in the milder disease forms, while insufficient to prevent GSL storage, may be capable of preventing the storage of water-soluble substrates.

Deleterious effects of GSL depletion. Slowing the rate of GSL synthesis may lower their levels in the plasma membrane of cells. Although consequences of this GSL depletion are unclear, the GalNAcT $T^{-1}$ mice provide some insight into the effects of total elimination of most complex gangliosides. The GalNAcT $T^{-/-}$mice have a normal life span and develop a near normal nervous system with only subtle conduction abnormalities (14). Recently, some degenerative changes in their axons and Schwann cells have been noted (30). Male infertility also results from impaired GSL synthesis. However, in the GalNAcT $T^{-1-}$ mice, the absence of certain gangliosides is absolute and occurs throughout embryonic development. This would not be the case in substrate deprivation therapy where reduction of GSL levels are unlikely to be reduced completely and where GSL reduction would be implemented after development of the nervous system.

The effects of GSL depletion in a compromised CNS may also be a concern. The 11-week-old double knockout mice with no GSL accumulation were unexpectedly less proficient on rotorod than the Hexb/- GalNAcT T/-- mice, even though the mice heterozygous for the disrupted $\mathrm{Gal}$ $N A c T$ allele were abnormally accumulating GSLs. A possible explanation is that the complete absence of complex gangliosides in the double knockout mice may have rendered CNS more sensitive to damaging effects of oligosaccharide storage. These results suggest that complex gangliosides may stabilize or protect the CNS from insult or injury. Caution should be taken, however, in directly extrapolating the results obtained in mice to humans.

The genetic model presented here validates the concept that substrate deprivation therapy can be highly effective in preventing or eliminating disease manifestations in a GSL storage disorder. Although the model also illustrated some potential limitations in the approach, overall the results advance substrate deprivation therapy as a new treatment paradigm for the GSL storage diseases.

\section{Acknowledgments}

We thank Jenn Reed for her expert help in preparing the figures. This work was supported in part by US Public Health Service grants RO1-NS 24453 and P30-HD 03110 (to K. Suzuki) and by grant SFB 284 from the Deutsche Forschungsgemeinschaft (to K. Sandhoff).
1. Kolter, T., and Sandhoff, K. 1998. Recent advances in the biochemistry of sphingolipidoses. Brain Pathol. 8:79-100.

2. Neufeld, E.F. 1991. Lysosomal storage diseases. Annu. Rev. Biochem. 60:257-280

3. Radin, N.S. 1996. Treatment of Gaucher disease with an enzyme inhibitor. Glycoconj. J. 13:153-157.

4. Platt, F.M., et al. 1997. Prevention of lysosomal storage in Tay-Sachs mice treated with $N$-butyldeoxynojirimycin. Science. 276:428-431.

5. Sango, K., Johnson, O.N., Kozak, C.A., and Proia, R.L. 1995. $\beta-1,4-N$ acetylgalactosaminyltransferase involved in ganglioside synthesis: cDNA sequence, expression, and chromosome mapping of the mouse gene. Genomics. 27:362-365.

6. Deng, C., Wynshaw-Boris, A., Zhou, F., Kuo, A., and Leder, P. 1996. Fibroblast growth factor receptor 3 is a negative regulator of bone growth. Cell. 84:911-921.

7. Sango, K., et al. 1996. Mice lacking both subunits of lysosomal $\beta$-hexosaminidase exhibit mucopolysaccharidosis and gangliosidosis. Nat. Genet. 14:348-352.

8. Starr, C.M., Masada, R.I., Hague, C., Skop, E., and Klock, J.C. 1996. Fluorophore-assisted carbohydrate electrophoresis in the separation, analysis, and sequencing of carbohydrates. J. Chromatogr. A. 720:295-321.

9. Kotani, M., Ozawa, H., Kawashima, I., Ando, S., and Tai, T. 1992. Generation of one set of monoclonal antibodies specific for a-pathway ganglio-series gangliosides. Biochim. Biophys. Acta. 1117:97-103.

10. Ozawa, H., et al. 1997. Generation and characterization of mouse monoclonal antibodies specific for N-linked neutral oligosaccharides of glycoproteins. Arch. Biochem. Biophys. 342:48-57.

11. Sango, K., et al. 1995. Mouse models of Tay-Sachs and Sandhoff diseases differ in neurologic phenotype and ganglioside metabolism. Nat. Genet. 11:170-176.

12. Huang, J.Q., et al. 1997. Apoptotic cell death in mouse models of GM2 gangliosidosis and observations on human Tay-Sachs and Sandhoff diseases. Hum. Mol. Genet. 6:1879-1885.

13. Capecchi, M.R. 1989. Altering the genome by homologous recombination. Science. 244:1288-1292.

14. Takamiya, K., et al. 1996. Mice with disrupted GM2/GD2 synthase gene lack complex gangliosides but exhibit only subtle defects in their nervous system. Proc. Natl. Acad. Sci. USA. 93:10662-10667.

15. Norflus, F., et al. 1998. Bone marrow transplantation prolongs life span and ameliorates neurologic manifestations in Sandhoff disease mice. $J$. Clin. Invest. 101:1881-1888.

16. Suzuki, K., Proia, R.L., and Suzuki, K. 1998. Mouse models of human lysosomal diseases. Brain Pathol. 8:195-215.

17. Gravel, R.A., et al. 1995. The $\mathrm{G}_{\mathrm{M} 2}$ gangliosidoses. In The metabolic and molecular basis of inherited disease. C.R. Scriver, A.L. Beaudet, W.S. Sly, and D. Valle, editors. McGraw-Hill. New York, NY. 2839-2879.

18. Yamanaka, S., et al. 1994. Targeted disruption of the Hexa gene results in mice with biochemical and pathologic features of Tay-Sachs disease. Proc. Natl. Acad. Sci. USA. 91:9975-9979.

19. Taniike, M., et al. 1995. Neuropathology of mice with targeted disruption of Hexa gene, a model of Tay-Sachs disease. Acta Neuropathol. 89:296-304.

20. Phaneuf, D., et al. 1996. Dramatically different phenotypes in mouse models of human Tay-Sachs and Sandhoff diseases. Hum. Mol. Genet. 5:1-14.

21. Brady, R.O. 1998. Therapy for the sphingolipidoses. Arch. Neurol. 55:1055-1056.

22. Beutler, E., and Grabowski, G.A. 1995. Gaucher disease. In The metabolic and molecular basis of inherited disease. C.R. Scriver, A.L. Beaudet, W.S. Sly, and D. Valle, editors. McGraw-Hill. New York, NY. 2641-2670.

23. Krivit, W., et al. 1998. Hematopoietic stem-cell transplantation in globoid-cell leukodystrophy. N. Engl. J. Med. 338:1119-1126.

24. Hoogerbrugge, P.M., et al. 1995. Allogeneic bone marrow transplantation for lysosomal storage diseases (comment). Lancet. 345:1398-1402.

25. Platt, F.M., Neises, G.R., Dwek, R.A., and Butters, T.D. 1994. Nbutyldeoxynojirimycin is a novel inhibitor of glycolipid biosynthesis. J. Biol. Chem. 269:8362-8365.

26. Leinekugel, P., Michel, S., Conzelmann, E., and Sandhoff, K. 1992. Quantitative correlation between the residual activity of $\beta$-hexosaminidase $A$ and arylsulfatase A and the severity of the resulting lysosomal storage disease. Hum. Genet. 88:513-523.

27. de Jong, J.G., et al. 1998. Oligosaccharide excretion in adult Gaucher disease. J. Inherit. Metab. Dis. 21:49-59.

28. Suzuki, K., Sango, K., Proia, R.L., and Langaman, C. 1997. Mice deficient in all forms of lysosomal $\beta$-hexosaminidase show mucoploysaccharidosis-like phenotype. J. Neuropathol. Exp. Neurol. 56:693-703.

29. Sukuki, Y., Sakuraba, H., and Oshima, A. 1995. $\beta$-galactosidase deficiency ( $\beta$-galactosidosis): $\mathrm{G}_{\mathrm{M} 1}$ ganglioside and Morquio $\mathrm{B}$ disease. In The metabolic and molecular bases of inherited disease. Vol. II. C.R. Scriver, A.L. Beaudet, W.S. Sly, and D. Valle, editors. McGraw-Hill. New York, NY. 2785-2823.

30. Sheikh, K.A., et al. 1998. Mice lacking complex gangliosides develop peripheral neuropathy. Soc. Neurosci. Abstr. 2:483. (Abstr.) 